\title{
Implication of HLA-DMA Alleles in Corsican IDDM
}

\author{
P. Cucchi-Mouillot ${ }^{1,4, \#, ~ S . ~ L a i ~}{ }^{2}$, C. Carcassi ${ }^{2}$, \\ P. Sorba ${ }^{3}$, M. Stuart-Simoni ${ }^{3}$, J.-P. Amoros ${ }^{3}$, \\ B. Genetet ${ }^{4}$, D. Haras ${ }^{1}$ and L. Contu ${ }^{2}$ \\ ${ }^{1}$ CEVAREN, Université de Corse, Campus \\ Grossetti, 20250 Corte, France \\ ${ }^{2}$ Cattedra di Genetica Medica, Università di \\ Cagliari, via San Giorgio 12, 09124 \\ Cagliari, Italia \\ ${ }^{3}$ Centre Hospitalier Général d'Ajaccio, \\ 20000 Ajaccio, France \\ ${ }^{4}$ Groupe Universitaire de Recherche en \\ Immunologie et Immunopathologie, EA 1257, \\ Université Rennes I, 2 av. du AR. Léon \\ Bernard, 35043 Rennes, France
}

\begin{abstract}
The HLA-DM molecule catalyses the CLIP/antigen peptide exchange in the classical class II peptide-binding groove. As such, DM is an antigen presentation regulator and may be linked to autoimmune diseases. Using PCR derived methods, a relationship was revealed between DM gene polymorphism and IDDM, in a Corsican population. The DMA*0101 allele was observed to confer a significant predisposition to this autoimmune disease while the DMA*0102 allele protected significantly. Experiments examining polymorphism of the HLADRB1 gene established that these relationships are not a consequence of linkage disequilibrium with HLADRB1 alleles implicated in this pathology. The study of the DMA gene could therefore be an additional tool for early IDDM diagnosis in the Corsican population.
\end{abstract}

KEYWORDS: diabetes, HLA-DMA, Corsica

\footnotetext{
\# Correspondence: Dr Patricia Cucchi-Mouillot-CEVAREN, Université de Corse, Campus Grossetti, 20250 Corte, France, Tel: 334954500 27, Fax: 334956105 51, E-mail: maury@univ-corse.fr
}

\section{INTRODUCTION}

The DMA and DMB genes have been grouped with the class II HLA genes [23] and code for the Dm $\alpha$ and $\beta$ chains, respectively. It is these chains which make up the DM molecule. The role of the DM molecule seems to differ from that of classical HLA-class II molecules as they are relatively sparsely expressed on the cell surface. The DM molecules have been found in specialised endosomes termed MIIC, which stands for MHC class II compartment [17], in which classical class II molecules are also observed associated with a peptide [20] or class II associated invariant chain peptide (CLIP). In this compartment, the DM molecule intervenes by catalysing CLIP/antigen peptide exchanges in the class II molecules [22] by fixation on these class II molecules [19]. This fixation would imply the stabilisation of empty class II molecules promoting binding of antigenic peptides [6]. Yet, in a low density endosome, another processing mechanism of complex class II-peptide formation, DM independent and using recycled class II molecules, has been described [8].

Regardless of the hypotheses examined, it has been established that the HLA-DM molecule acts on antigen processing and that, without it, the class II non recycled molecules are incapable of presenting exogenous peptides: they remain associated to CLIP [16]. Moreover, a defect in the DM molecule could imply an augmentation of this low-density endosome processing which could lead to a wrong immune response such as the immune system failure which leads to IDDM. The aim of the present study was to examine DMA gene polymorphism in IDDM patients in a Corsican population group. Corsica is an isolated 
geographic region. In light of this, the probability that control and patient groups are of a different origin is limited. Moreover, to limit this type of bias, only third generation Corsican subjects were considered for the purposes of this study.

\section{SUBJECTS AND METHODS}

\section{Subjects}

A control group was composed of 48 healthy subjects (mean age: 53 years, range: $17-71$ years, sex ratio: $1 / 2$ ). The sick subject group contained 23 insulin-dependent diabetic mellitus (IDDM) subjects (mean age: 33 years, range: $17-44$ years, sex ratio: $1 / 2$ ).

Mean duration of IDDM was 12.5 years (range: 1-25 years). Among these subjects, six had a family history of IDDM or NIDDM in their immediate family and two have a family history of other autoimmune diseases (thyroid). In addition, two of the IDDM subjects suffer from thyroid pathologies.

All subjects (control and IDDM subjects) were sampled by the "Centre Hospitalier Général d'Ajaccio" in accordance with the directives of the "Centre pour la Protection des Personnes en Recherche Biologique" of Nice. Although the propriety of these directives is unquestionable, their application reduced the number of participants available for study.

These subjects were all unrelated and third generation Corsicans: they were born in Corsica as were their parents and grandparents. The low number of subjects is best explained by the low number of Corsican inhabitants $(249,737$ in 1990) as IDDM incidence is the same in Corsica as it is on the main land: 7/100,000 new cases per year [15]. In addition, of possible diabetic subjects only approximately $1 / 4$ of these are third generation Corsicans and the Corsican health care infrastructure does not make it possible to access all of these.

\section{DMA gene typing}

The methods used have been either developed or perfected in Prof. L. Contu's laboratory (Carcassi et al., unpublished data). Briefly, the DNA is extracted by salting out a $5 \mathrm{ml}$ blood sample and then amplified by classical PCR at the level of the third exon of the DMA gene. The primers used were DMA-3L (GGG TTT CCT ATC GCT GAA GTG; 5' terminal) and DMA3R (CCA ATA GGC AAT TGC TGT GTA; 3' terminal). The amplification mixture contained $0.5 \mu \mathrm{mol}$ of any given primer (Genosys), $500 \mathrm{ng}$ of genomic DNA, $3.5 \mathrm{mM}$ of $\mathrm{MgCl}_{2}$ (Boehringer Mannheim), $0.2 \mathrm{mM}$ of dNTP (Boehringer Mannheim), 1U of Taq DNA polymerase (Boehringer Mannheim) and its buffer. The amplification was performed in a 9600 amplificator (Perkin Elmer Cetus) with 32 cycles of $30 \mathrm{~s}$ at $94{ }^{\circ} \mathrm{C}, 50 \mathrm{~s}$ at $65^{\circ} \mathrm{C}$ and $30 \mathrm{~s}$ at $72{ }^{\circ} \mathrm{C}$. Results were revealed using UV on a $2 \%$ agarose gel (285 bp band) with $0.5 \mu \mathrm{g} / \mathrm{ml}$ ethidium bromide. DMA allele typing was performed by PCR-SSO. The DMA amplification material, after control, was fixed on a Hybond $\mathrm{N}+$ membrane with an automatic system (Hydra microdispenser, Robbins Scientific). The membranes were then dried before denaturation by adding $0.4 \mathrm{~N} \mathrm{NaOH}$ for 5 min followed by a 10 min wash with $0.2 \mathrm{X}$ salt sodium chloride (SSC, Biorad). After a 20 min earlyhybridisation at $50{ }^{\circ} \mathrm{C}$, the probes were hybridised for $2 \mathrm{~h}$ at $50^{\circ} \mathrm{C}$ in $6 \mathrm{X}$ salt sodium phosphate EDTA (SSPE, Biorad), $5 \mathrm{X}$ Denhardt's solution (Biorad), 0.1\% Sarcosin (Biorad) and $0.02 \%$ sodium dodecyl sulfate (SDS, Biorad). The probes used were DM1 5'CAT CAT TCC GTC CCT GTG3', DM2 5'CAT CAT TCC ATC CCT GTG3', DM3 5'GCT GTC GAT GCA CTC AGC3', DM4 5'GAA ATT GAC CGC TAC ACA3', DM5 5'GAA ATT GAC CAC T-AC ACA3' and DM6 5'GAA ATT GAC TGC TAC ACA3' (Genosys). They were all labelled beforehand with digoxygenin-dUTP (Boehringer Mannheim). 
The hybridised membranes were washed $30 \mathrm{~min}$ in tetra methyl ammonium chloride (TMAC, Sigma) at $52{ }^{\circ} \mathrm{C}$ for DM2, 4,5 and 6 and at $58{ }^{\circ} \mathrm{C}$ for DM1 and 3. Detection was performed with the Boehringer Mannheim's Dig Luminescent detection kit. The results were then analysed on membrane radiographs.

\section{DRB1 gene typing}

This typing was performed by the INNO-LIPA "DRB key" kit [1] distributed by Innogenetics (Murex, France). For the DR4 subtyping, we used the INNO-LIPA "DRB1*04" kit. Briefly, the samples were amplified by PCR with biotinylated primers. Then, a reverse dot blot was performed consisting of hybridisation between probes fixed on a nitro-cellulose strip and the previously amplified DNA. The reactivity with the probes was different for each allele. Hybridisation was detected by addition of streptavidin-phosphatase alkaline complex, followed by the presence of NBT-BCIP substrate. Genotyping was derived from the combination of probes giving a positive reaction. Allele clustering was carried out to facilitate analysis. Indeed, it was not possible to distinguish between certain alleles using this method. Thus, we have respectively clustered: DRB $1 * 0101, * 0102$, $* 0103$ and $* 0104$ alleles; DRB1*03011, *0302 and *0304 alleles; DRB1*0405 and *0408 alleles; DRB1*1301, *1302, *1308, *1310, $* 1317$ and *1319 alleles; DRB1*1401,*1407, $* 1410$ and *1411 alleles; DRB1*1501, *1503 and $* 1504$ alleles; and DRB1*1601, $* 1602$ and
*1605 alleles, under the notations DRB $1 * 0101$, DRB1*03011, DRB1*0405, DRB1*1301, DRB1*1401, DRB1*1501 and DRB1*1601.

\section{Statistical analysis}

Comparison of the results for genotypic analysis was performed by the $\chi^{2}$ Pearson test with Yates' correction where necessary. The relative risk (RR) was calculated by the Haldane's formula [9]. Allele analysis was performed using the HLASTAT2 developed by Marc Busson. In this software, the possibility of linkage disequilibrium is estimated by the $\Delta$ test using the formula:

$$
\Delta_{A B}=\sqrt{F 4}-\sqrt{(F 2+F 4)(F 3+F 4)}
$$

where $\mathrm{F} 2$ is the frequency of subjects with $\mathrm{A}$ allele and without $\mathrm{B}$ allele, $\mathrm{F} 3$ is the frequency of subjects with $B$ allele and without $A$ allele and F4 is the frequency of subjects without A or B alleles.

In this study, we have corrected $\mathrm{p}$ values using Bonferoni inequality [7].

\section{RESULTS}

\section{Determination of potential HLA-DMA allelic markers in IDDM}

As can be seen in Table 1, the DMA*0101 allele seems to be a significantly predisposing characteristic of IDDM while the DMA*0102 allele appears to significantly protect from this

Table 1

DMA allele associations with IDDM.

\begin{tabular}{ccccccccc}
\hline Allele & \multicolumn{2}{c}{ IDDM $(2 \mathrm{n}=46)$} & \multicolumn{2}{c}{ Controls $(2 \mathrm{n}=96)$} & \multirow{2}{*}{$\chi^{2}$} & $\mathrm{p}$ & $\mathrm{p}_{\mathrm{c}}$ & $\mathrm{RR}$ \\
\cline { 2 - 6 } DMA*0101 & + & - & + & - & & & \\
& $96 \%$ & $4 \%$ & $76 \%$ & $24 \%$ & 8.2 & $<0.005$ & $<0.02$ & $\begin{array}{c}5.69 \\
\text { predisposing }\end{array}$ \\
DMA*0102 & $4 \%$ & $96 \%$ & $20 \%$ & $80 \%$ & 5.9 & $<0.02$ & $<0.05$ & $\begin{array}{c}0.22 \\
\text { protector }\end{array}$ \\
DMA*0103 & $0 \%$ & $100 \%$ & $4 \%$ & $96 \%$ & 2.0 & n. s. & n. s. & \\
\hline
\end{tabular}

+: subject with studied allele, - : subject without studied allele. $n$. s.: not significant, $\mathrm{p}_{\mathrm{c}}: \mathrm{p}$ with Bonferoni correction. 
Table 2

DMA genotype associations

\begin{tabular}{|c|c|c|c|c|c|c|c|c|}
\hline \multirow{2}{*}{ Genotype } & \multicolumn{2}{|c|}{ IDDM $(n=23)$} & \multicolumn{2}{|c|}{ Controls $(\mathrm{n}=48)$} & \multirow{2}{*}{$\chi^{2}$} & \multirow{2}{*}{$\mathrm{p}$} & \multirow{2}{*}{$\mathrm{p}_{\mathrm{c}}$} & \multirow{2}{*}{$\mathrm{RR}$} \\
\hline & + & - & + & - & & & & \\
\hline $\mathrm{DMA}^{*} 0101 / 0101$ & $91 \%$ & $9 \%$ & $60 \%$ & $40 \%$ & 7.1 & $<0.009$ & $<0.04$ & $\begin{array}{c}5.68 \\
\text { predisposing }\end{array}$ \\
\hline $\mathrm{DMA}^{*} 0101 / 0102$ & $9 \%$ & $91 \%$ & $31 \%$ & $69 \%$ & 4.3 & $<0.04$ & n. s. & $\begin{array}{c}0.25 \\
\text { protector }\end{array}$ \\
\hline $\mathrm{DMA}^{*} 0101 / 0103$ & $0 \%$ & $100 \%$ & $6 \%$ & $94 \%$ & 4.3 & n. s. & & \\
\hline DMA*0102/0103 & $0 \%$ & $100 \%$ & $2 \%$ & $98 \%$ & 4.5 & n. s. & & \\
\hline
\end{tabular}

+: subject with studied genotype, -: subject without studied genotype. n. s.: not significant, $\mathrm{p}_{\mathrm{c}}$ : $\mathrm{p}$ with Bonferoni correction.

Table 3

Linkage disequilibrium between DMA and DRB1 genes

\begin{tabular}{ccccc}
\hline Allele A & Allele B & $\Delta_{\mathrm{AB}}$ & $\chi^{2}$ & $\mathrm{p}$ \\
\hline DRB1*08041 & DMA*0101 & -0.030 & 6.3 & 0.012 \\
DRB1*1001 & DMA $^{*} 0101$ & -0.034 & 10.2 & 0.001 \\
DRB $1 * 1001$ & DMA*0102 $^{*}$ & 0.021 & 4.6 & 0.032 \\
DRB $1 * 1401$ & DMA*0102 & 0.021 & 4.6 & 0.032 \\
\hline
\end{tabular}

The negative linkage disequilibrium is in italics. The notation DRB1*1401 corresponds to the clustering of DRB1*1401, *1407, *1410 and *1411 alleles; DRB1*1501, *1503 and *1504 alleles; and DRB1*1601, *1602 and *1605 alleles.

disease. The DMA*0103 does not appear to be very well represented in the Corsican population and the DMA*0104 is not present in our group of subjects.

\section{HLA-DMA genotypic marker}

In Table 2, we can observe that persons with the DMA*0101/0101 genotype have a significantly greater risk of developing IDDM. Conversely, the DMA*0101/0102 genotype seems to protect them from this disease. The other genotypes were poorly or not represented in our population group.

\section{Study of linkage disequilibrium between DRB1 and DMA genes}

The results generated in our laboratory (unpublished data) show that: DRB1*03011 and DRB1*0402 confer susceptibility to IDDM. In
Table 3, where only the significant results have been presented, there is no positive disequilibrium between DRB1 and DMA allelic markers of IDDM.

\section{DISCUSSION}

The polymorphism of HLA-DMA at the population level has received very little attention in the literature as its intervention in peptide presentation processing has only recently been established [11]. The comparison of DMA gene allelic distribution between control and diabetic subjects reveals significant differences between these two groups (Table 1). This implies that certain alleles may be possible markers of this disease. In particular, the DMA*0101 allele would appear to confer a significant predisposition to IDDM while the DMA*0102 
allele would seem to significantly protect from this pathology.

It is therefore interesting to determine if certain genotypes are also implicated in this pathology. As can be observed in Table 2, persons with the DMA*0101/0101 genotype have a significantly greater risk of developing the studied autoimmune disease whereas people possessing the DMA*0101/0102 genotype appear to be significantly protected. The DMA*0102/0102 genotype, however, does not seem to be significantly more abundant in the control subjects than in the sick subjects. The low relative abundance of this allele can help to explain this ambiguity. Furthermore, it is possible that the DMA*0101 allele leads to a defect in the DM molecule while the DMA*0102 allele generates a "good" DM molecule. Thus, if a subject has a DMA*0102 allele, a good DM molecule will be present at his cell surfaces and will prevent autoimmune processing and this even if he also possesses a DMA*0101 allele. Yet, this relationship between DMA*0101/0102 presence and IDDM protection was not confirmed after $\mathrm{p}$ correction. This may be due to the small size of the study group. Moreover, a protective role for DMA*0102 has already been described in membranous nephropathy where decreases in the DMA*0102 phenotype have been observed [4].

Among the possible markers of IDDM are alleles of the class II genes such as HLA-DR [10]. The test for linkage disequilibrium (Table 3) shows that, even if linkages exist between DMA and DRB1 alleles, none of these explain the susceptibility (or protection) conferred by the DMA alleles towards (or against) IDDM. Indeed, DRB1 marker alleles for this disease in the Corsican population group is not in positive linkage disequilibrium with the DMA markers.

In this context, it is possible that DMA allelic polymorphism intervenes directly in IDDM predisposition, and the role of antigen processing would therefore seem to be significant in this disease. The DM allelic polymorphism corresponds to a structural difference located in the extra-cytoplasmic region nearest the membrane $[2,3,18]$. It is therefore reasonable to assume that this domain intervenes during the linkage of DM with the classical class II molecules. This linkage allows the catalysis of CLIP dissociation and/or of antigen peptide fixation in the class II molecules [6,21,22]. Furthermore, a defect in this linkage will prevent the peptide editor function of DM described by Kropshofer et al. [12]. MHC class II molecules encounter peptides generated by proteolysis of self-proteins from endocytic pathways or from internalised exogenous antigens [5]. In the absence of DM and at an endosomal pH, CLIPclass II dissociation is possibly mediated by the $\mathrm{N}$-terminal fragment of CLIP [11]. This will result in a partial loading with self-peptides of certain human class II alleles [13]. This could indicate that an allelic form of DMA (such as DMA*0101) along with certain allelic forms of class II (DRB1*03011 for instance) prevents the DM-DR fixation. This would imply an amplification of the presentation of self-peptides, such as certain auto-antigens (Glutamic Acid Decarboxylase, among others), which can give rise to autoimmune disorders (such as IDDM).

It will be of interest to determine if this predisposition and protection is a characteristic of the Corsican population group, however. For example, in the Mongoloid population, the linkage disequilibrium found for DMA is, at present, different from that observed in the Corsican population [14]. To solve this question, future research will involve the study of other populations such as the Sardinian population. Possessing a maximum amount of genetic information concerning different populations would be a great asset in the development of an early diagnosis strategy. Such a strategy could be used to minimise or prevent secondary complications by adapting the treatment in time.

In conclusion, the HLA-DM molecules which are involved in antigen processing may be linked to susceptibility to IDDM. This link, observed in a Corsican population, does not appear to be due to linkage disequilibrium with an HLA-DRB1 allele. The identification of persons possessing a predisposition to autoimmune diseases is important to delay, reduce or even avoid the 
appearance of secondary complications which are very disabling for the patient. The identification of DMA as a new IDDM marker will bring added security to the early diagnosis of this disease.

\section{Acknowledgments}

We wish to express our thanks to the "Institut National de la Santé et de la Recherche Médicale", the "Université de Corse" and the "Università di Cagliari" for their support. Thanks also go out to Prof. V. Lotteau and Dr. J. Maury for their constructive criticism of the manuscript and to Dr. E. Quelvennec and Dr. M. Busson for their explanations of HLASTAT2.

\section{References}

[1] Buyse, I., Decorte, R., Cuppens, H., Semana, G., Emonds, M.P., Marynen, P. and Cassiman, J.J. Rapid typing of class II HLA antigens using the polymerase chain reaction and reverse dot blot hybridization. Tissue Antigens 41, (1993) 1-14.

[2] Carrington, M. and Harding, A. Sequence analysis of two novel HLA-DMA alleles. Immunogenetics 40, (1994) 165.

[3] Carrington, M., Yeager, M. and Mann, D. Characterization of HLA-DMB polymorphism. Immunogenetics 38, (1993) 446-449.

[4] Chevrier, D., Giral, M., Perrichot, R., Latinne, D., Coville, P., Muller, J.Y., Soulillou, J.L. and Bignon, J.D. Idiopathic and secondary membranous nephropathy and polymorphism at TAP1 and HLA-DMA loci. Tissue Antigens 50, (1997) 164-169.

[5] Chicz, R.M., Urban, R.G., Gorga, J.C., Vignali, D.A.A., Lane, W.S. and Stromminger, J.L. Specificity and promiscuity among naturally processed peptides bound to HLA-DR alleles. Journal of Experimental Medicine 178, (1993) $27-$ 47.

[6] Denzin, L., Hammond, C. and Cresswell, P. HLADM interactions with intermediates in HLA-DR maturation and a role for HLA-DM in stabilising empty HLA-DR molecules. Journal of Experimental Medicine 184, (1996) 2153-2165.

[7] Dyer, P. and Warrens, A., Design and interpretation of studies of the major histocompatibility complex in disease. In: Lechler,
L. (ed.) HLA and disease, 1. London: Academic Press Limited, (1994) 93-121.

[8] Griffin, J., Chu, R. and Harding, C. Early endosomes and a late endocytic compartment generate different peptide-class II MHC complexes via distinct processing mechanisms. Journal of Immunology 158, (1997) 1523-1532.

[9] Haldane, J.B.S. The estimation and significance of the logarithm of a ratio of frequencies. Annals of Human Genetics 20, (1956) 309-311.

[10] Haras, D., Silicani-Amoros, J.P. and Amoros, J.P. HLA and susceptibility to insulin-dependent diabetes mellitus on the island of Corsica. Tissue Antigens 44, (1994) 129-133.

[11] Kropshofer, H., Vogt, A.B. and Hämmerling, G.J. Structural features of invariant chain CLIP region controlling rapid release from HLA-DR molecules and inhibition of peptide binding. Proceeding of the National Academy Science of the USA 92, (1995) 8313-8317.

[12] Kropshofer, H., Vogt, A.B., Moldenhauer, G., Hammer, J., Blum, J.S. and Hämmerling, G.J. Editing of HLA-DR-peptide repertoire by HLADM. The EMBO Journal 15, (1996) 6144-6154.

[13] Kropshofer, H., Vogt, A.B., Stern, L.J. and Hämmerling, G.J. Self-release of CLIP in peptide loading of HLA-DR molecules. Science 270, (1995) 1357-1359.

[14] Kuwata, S., Yanagisawa, M., Nakagawa, H., Saeki, H., Etoh, T., Miyamoto, M., Juji, T., HLADM gene polymorphisms in atopic dermatitis. Journal of Allergy and Clinical Immunology 98, (1996) S192-S200.

[15] Levy-Marshal, C., Papoz, L., De Beaufort, C., Doutreix, J., Froment, V., Voirin, J., Collignon, A., Garros, B., Schleret, Y. and Czernichow, P. Incidence of juvenile Type 1 (insulin-dependent) diabetes mellitus in France. Diabetologia 33, (1990) 465-469.

[16] Morris, P., Shaman, J., Attaya, M., Amaya, M., Goodman, S., Bergman, C., Monaco, J.J. and Mellins, E. An essential role for HLA-DM in antigen presentation by class II major of histocompatibility molecules. Nature 368, (1994) 551-554.

[17] Nijman, H.W., Kleijmeer, M.J., Ossevoort, M.A., Oorschot, V.M.J., Vierboom, M.P.M., van de Keur, M., Kenemans, P., Kast, W.M., Geuze, H.J. and Meleif, C.J.M. Antigen capture and major histocompatibility class II compartments of freshly isolated and cultured human blood dendritic cells. Journal of Experimental Medicine 182, (1995) 163-174. 
[18] Sanderson, F., Kleijmeer, M.J., Kelly, A., Verwoerd, D., Tulp, A., Neefjes, J.J., Geuze, H.J. and Trowsdale, J. Accumulation of HLA-DM, a regulator of antigen presentation, in MHC class II compartments. Science 266, (1994) 1566-1569.

[19] Sanderson, F., Thomas, C., Neefjes, J. and Trowsdale, J. Association between HLA-DM and HLA-DR in vivo. Immunity 4, (1996) 87-96.

[20] Sette, A., Ceman, S., Kubo, R.T., Sakaguch, K., Appella, E., Hunt, D.F., Davis, T.A., Michel, H., Shabanowitz, J., Ruddersorf, R., Grey, H.M. and DeMars, R. Invariant chain peptides in most HLADR molecules of an antigen-processing mutant. Science 258, (1992) 1801-1804.
[21] Sherman, M.A., Weber, D.A. and Jensen, P.E. DM enhances peptide binding to class II MHC by release of invariant chain-derived peptide. Immunity 3, (1995) 197.

[22] Sloan, V.S., Cameron, P., Porter, G., Gammon, M., Amaya, M., Mellins, E. and Zaller, D.M. Mediation by HLA-DM of dissociation of peptides from HLA-DR. Nature 375, (1995) 802-806.

[23] Stern, L.J., Brown, J.H., Jardetzky, T.S., Gorga, J.C., Urban, R.G., Strominger J.L. and Wiley, D.C. Crystal structure of the human class II MHC protein with HLA-DR1 complexed with an influenza virus peptide. Nature 368, (1994) 215221. 


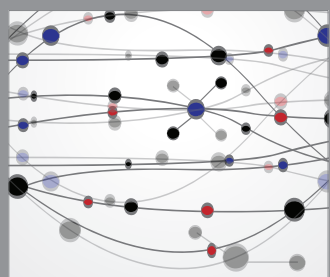

The Scientific World Journal
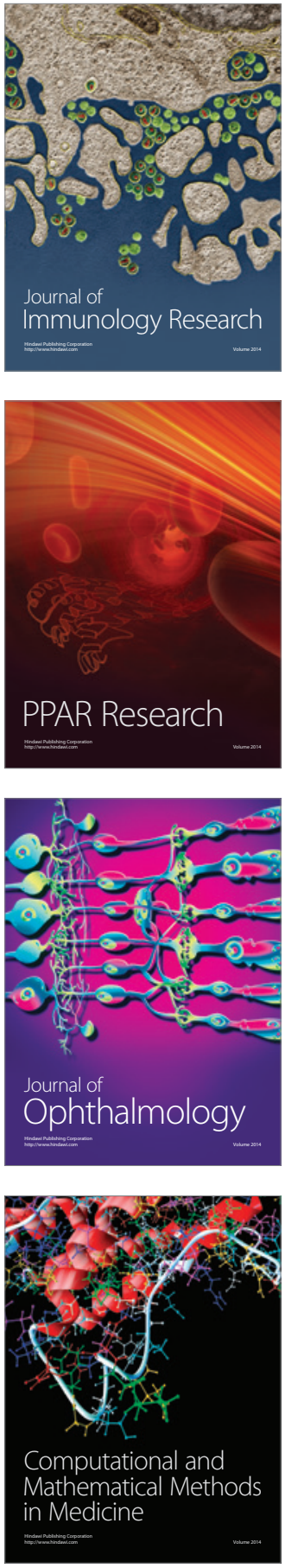

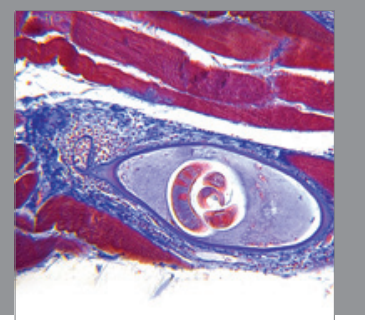

Gastroenterology

Research and Practice
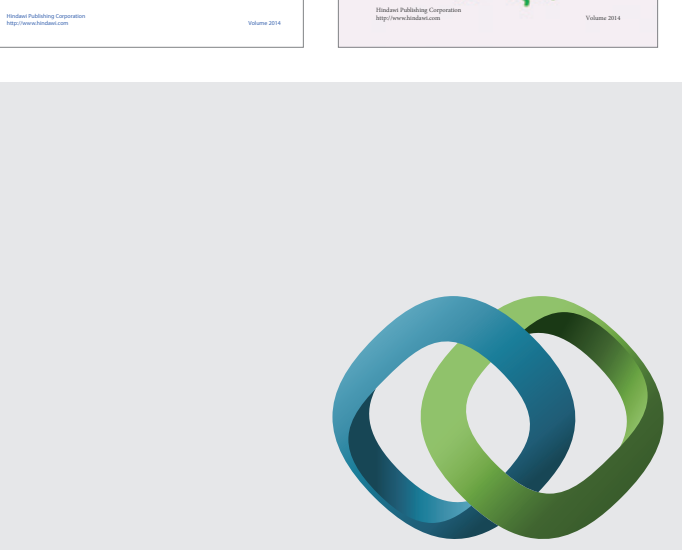

\section{Hindawi}

Submit your manuscripts at

http://www.hindawi.com
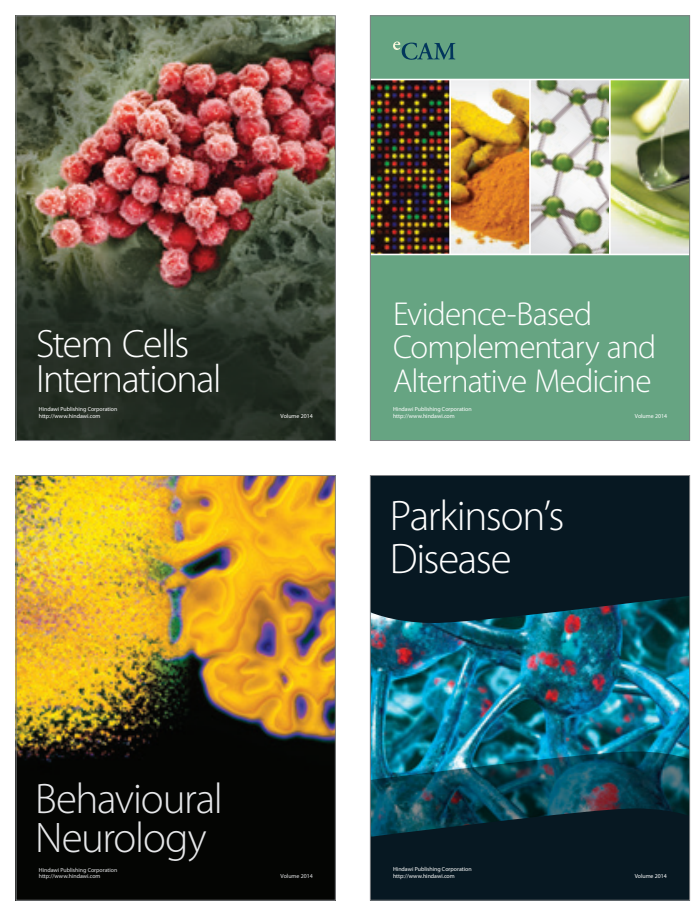

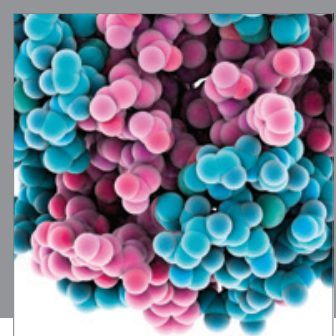

Journal of
Diabetes Research

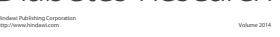

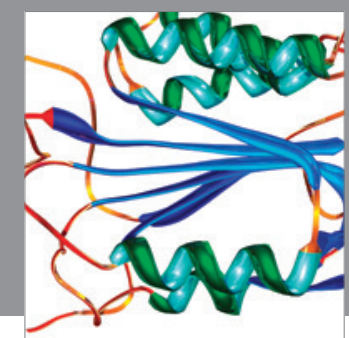

Disease Markers
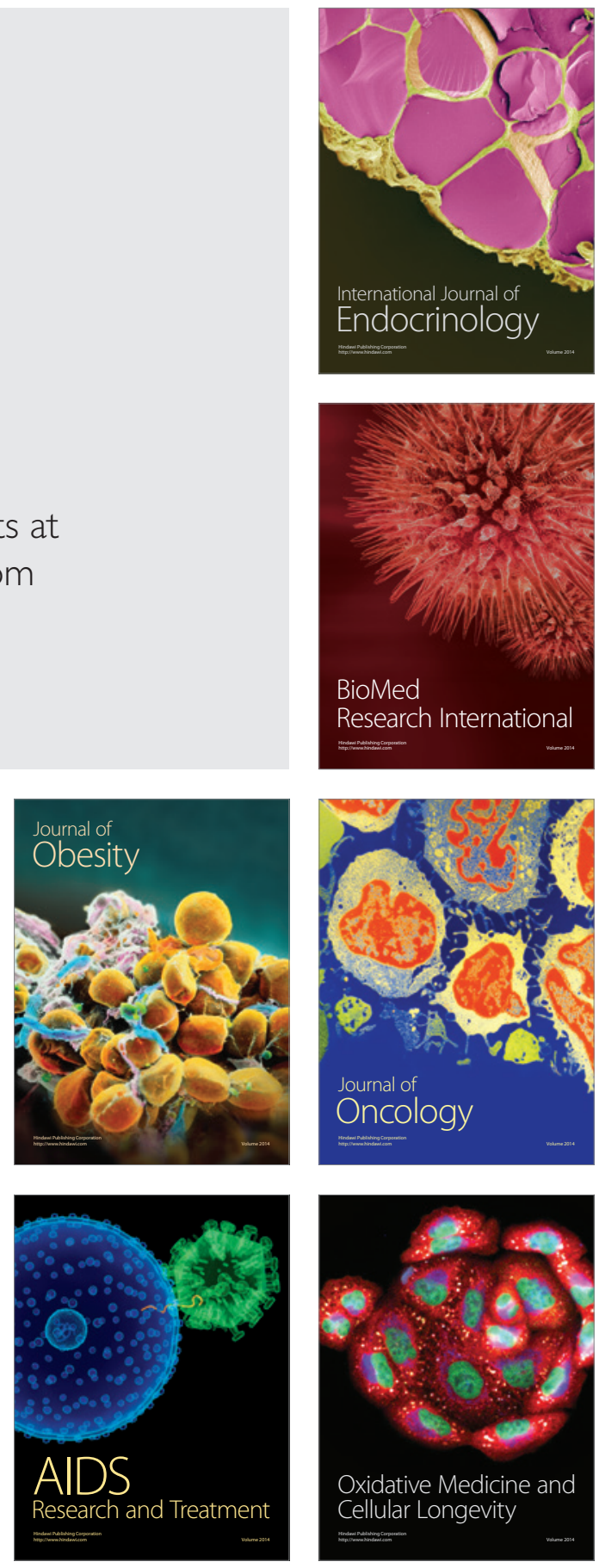